Original Article

\title{
Wii Fit balance training or progressive balance training in patients with chronic stroke: a randomised controlled trial
}

\author{
Gozde Iyigun YataR ${ }^{1)^{*}}$, Sibel Aksu Yildirim ${ }^{2)}$ \\ 1) Department of Physiotherapy and Rehabilitation, Eastern Mediterranean University: Famagusta CY \\ 99500, Cyprus \\ 2) Department of Physiotherapy and Rehabilitation, Hacettepe University, Turkey
}

\begin{abstract}
Purpose] The aim of this study was to compare the effects of Wii Fit balance training (WBT) and progressive balance training (PBT) approaches on balance functions, balance confidence, and activities of daily living in chronic stroke patients. [Subjects] A total of 30 patients were randomized into the WBT $(n=15)$ and PBT $(\mathrm{n}=15)$ groups. [Methods] All of the subjects received exercise training based on a neurodevelopemental approach in addition to either Wii Fit or progressive balance training for total of 1 hour a day, 3 days per week for 4 weeks. Primary measurements were static balance function measured with a Wii Balance Board and dynamic balance function assessed with the Berg Balance Scale, Timed Up and Go test, Dynamic Gait Index, and Functional Reach Test. Secondary measures were balance confidence assessed with the Activities-specific Balance Confidence scale and activities of daily living evaluated with the Frenchay Activity Index. [Results] There was not remarkable difference between the two treatments in dynamic balance functions, balance confidence, and activities of daily living. [Conclusion] Although both of the approaches were found to be effective in improving the balance functions, balance confidence, and activities of daily living, neither of them were more preferable than the other for the treatment of balance in patients with chronic stroke.

Key words: Stroke, Wii Fit, Balance treatment
\end{abstract}

(This article was submitted Oct. 27, 2014, and was accepted Dec. 11, 2014)

\section{INTRODUCTION}

World stroke incidence studies have shown that there has been a $42 \%$ decrease in stroke incidence in high-income countries and more than a $100 \%$ increase in low-to middleincome countries. Early stroke case fatality has decreased in both high-income and low-to middle-income countries ${ }^{1)}$. Despite the increase in stroke incidence, the decrease in mortality rate leads to an increase in people living with disabilities. Therefore, stroke constitutes the leading cause of serious, complex, and long-term adult disability ${ }^{2,3)}$.

Although $15-30 \%$ of the stroke survivors become permanently disabled, $50-70 \%$ of stroke patients regains functional independence and mostly regains walking ability ${ }^{4,5)}$. Due to residual functional disabilities such as impaired balance and motor weakness, patients with stroke may walk with an abnormal pattern. A study by Jorgensen et al. showed that $73 \%$ stroke patients fell in the six months after a stroke, that $21 \%$ fell after 6 months, and that over half of all reported falls

*Corresponding author. Gozde Iyigun Yatar (E-mail: gozde. yatar@emu.edu.tr)

C2015 The Society of Physical Therapy Science. Published by IPEC Inc. This is an open-access article distributed under the terms of the Creative Commons Attribution Non-Commercial No Derivatives (by-ncnd) License $<$ http://creativecommons.org/licenses/by-nc-nd/3.0/> occurred during walking activities due to problems such as loss of balance, misjudgement, and foot dragging ${ }^{6-8}$.

Balance deficits like reduced postural stability during quiet standing, delayed and less coordinated responses to internal and external balance perturbations, and increased weight bearing on the unaffected limb are one of the main risk factors for falls after stroke ${ }^{9-11)}$. Together with the increased risk of falling, fear of falling increases, self-confidence decreases, and individual autonomy and participation in social activities reduces. Therefore, patients become more dependent on caregivers, and as a result, quality of life decreases. The rehabilitation approaches aiming to increase the balance functions of patients promotes reintegration into the community, recreational and daily life activities, positive behavioral changes, and social acceptance of the patients ${ }^{12,13)}$.

Balance rehabilitation programs after stroke were found to be effective in enhancing functional recovery; on the other hand, the limited resources of health-care systems hamper the implementation of intensive practice ${ }^{14,15)}$. Therefore, innovative rehabilitation technologies including virtual reality systems are currently being used in stroke rehabilitation mainly because they provide an enriched environment, taskspecific goals, and repetitive practice ${ }^{16,17)}$. These systems may decrease the amount of time spent for one-to-one sessions with physiotherapists and may provide patients with the opportunity to use the systems at home.

Currently, Nintendo Wii Fit, video game technology us- 
ing virtual reality, has become a very popular rehabilitation approach in balance treatment. In the Wii Fit games, patients are directed to shift their weight anteriorly, posteriorly, and laterally within a center of pressure (COP) range in order to reach a target and to enhance their limits of stability. The Wii Fit games have been used in the literature due to their effects in improving motor skills and postural control by using visual-perceptual systems, providing information about the performance, showing the direction, speed and acceleration changes, and being interactive, motivating, useful and cheap $^{18-20)}$.

Few studies have used the Wii Fit method for balance treatment in chronic stroke patients. Two case report studies have demonstrated that static and dynamic balance can be improved with the Wii Fit system in patients with stroke ${ }^{21,22)}$. In a previous randomized controlled study in which standard rehabilitation plus virtual reality balance training with Wii Fit was compared with standard rehabilitation only greater improvement was observed in dynamic balance ${ }^{23)}$. This may be because of the disparity in the duration (length of session) and intensity (massed practice) of the treatment in the two groups. Therefore, it was expecting that more improvement would be obtained in the experimental group due to more intensive treatment. The aim of this study was to compare the effectiveness of game technology based Wii Fit balance training (WBT) and progressive balance training (PBT) in addition to a neurodevelopmental treatment program on static and dynamic balance functions, activity specific balance confidence, and activities of daily living in patients with chronic stroke.

\section{SUBJECTS AND METHODS}

Individuals with stroke admitted to a physiotherapy and rehabilitation department over a period of 12 months were considered for inclusion in this study. The study was approved by the local Ethics Committee for Medical, Surgery and Drug Research (LUT 11/01), and written informed consent was obtained from all patients prior to data collection.

Thirty-three patients with chronic stroke enrolled in the rehabilitation program. The criterion for inclusion was first ever stroke with hemiparesis ( $\geq 6$ months). Patients were excluded if they had any other physical problem or epilepsy, moderate to severe cognitive deficits as evaluated by the Mini Mental State Examination test (MMSE) ( $\leq 20$ points), severe depression as measured by the Beck Depression Inventory (BDI) ( $\geq 30$ points), and were unable to walk independently according to the Modified Rankin Scale (MRS) ( $>3$ points). Participants were randomly allocated to one of two different treatment groups: PBT and WBT. A simple randomization method was used to allocate patients in each group according to registration number (even numbers, PBT group; odd numbers, WBT group). Figure 1 shows the patient profile for the study.

A neurodevelopmental treatment, a problem solving and analytical approach, was applied to each group. The treatment programs were planned considering the functional level, individual needs, and demands of the patients based on selective movement as a basis of functional activity and successful goal acquisition ${ }^{24)}$. The details of the NDT are given

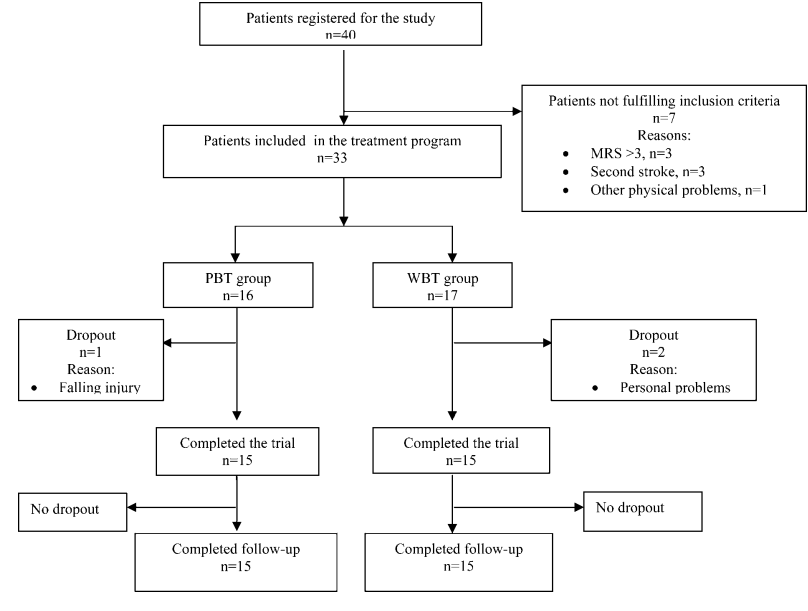

Fig. 1. Study profile

in Appendix 1. Patients assigned to the WBT group received a 1 hour treatment program consisting of a 30-minute neurodevelopmental training program and 30-minute Wii balance training program for a total of 12 sessions, which were held 3 days a week for 4 weeks. The details of the WBT are given in Appendix 2. Patients assigned to the PBT group received a 1 hour treatment program consisting of a 30 -minute neurodevelopmental training program and 30-minute progressive balance training program for a total of 12 sessions, which were held 3 days a week for 4 weeks. The details of the PBT are given in Appendix 3.

The descriptive variables of the patients including age, gender, body mass index, duration of stroke, and affected side were recorded before the treatment. All participants were assessed at baseline (week 0), after the treatment (week 4), and one month post treatment (week 8).

Primary measurements were static and dynamic balance function tests. The static balance, that is the mediolateral weight distribution on the paretic and nonparetic extremities, was measured with a Wii Balance Board (WBB), which has characteristics similar to laboratory-based force platform (FP) systems that contain four transducers used to assess weight distribution and $\mathrm{COP}^{25)}$.

Dynamic balance was measured with four balance tests reflecting different aspects of balance: the Berg Balance Scale, Timed Up and Go Test, Dynamic Gait Index, and Functional Reach Test.

The Berg Balance Scale (BBS), which is a psychometrically sound measure of balance impairment post stroke, was used to assess functional balance of the patients ${ }^{26,27)}$. The test is a 14-item objective measure used to assess the balance performance of patients during functional tasks ranging from sitting to standing on one foot ${ }^{28)}$.

The Timed Up and Go Test (TUG) was used to measure the functional mobility level of the patients. The time taken to complete the task (standing up from a chair, walking 3 meters, turning around, walking back, and sitting down) was recorded in this test $\mathrm{t}^{29,30)}$.

The Dynamic Gait Index (DGI), which assesses an individual's ability to modify balance while walking in the 
presence of external demands, was used to assess balance and gait ability of the patients ${ }^{31,32}$.

The Functional Reach Test (FRT), which consists of measurement of the maximal distance one can reach forward beyond arm's length while maintaining a fixed base of support in the standing position, was used to measure the stability limits of the patients ${ }^{33)}$.

The secondary measures were balance confidence and activities of daily living. The balance confidence of the patients was measured with the Activities-specific Balance Confidence (ABC) scale developed to measure the confidence of subjects when performing various ambulatory activities without falling ${ }^{34)}$. The activities of daily living of the patients were evaluated with the Frenchay Activity Index (FAI), which contains 3 factors (indoor domestic activities, outdoor domestic activities and outdoor social activities) related to the self care and mobility of patients ${ }^{35}$.

We calculated that the required sample size was $30 \mathrm{sub}-$ jects for $90 \%$ power with a $5 \%$ significance level. The results were analyzed with the SPSS 15.00 software program. The variables are presented as the mean \pm standard deviation (X $\pm \mathrm{SD}$ ). The differences within groups were tested using the Wilcoxon signed-rank test, and those between groups were tested using the Mann-Whitney nonparametric test. The Friedman test was used for repeated measurements, and Bonferroni correction was used to assess changes in balance functions from week 0 to week 8 between the groups. The $95 \%$ level of confidence ( $\alpha=0.05$, or the margin of error) was used for the assumptions to identify differences in the variance analysis.

\section{RESULTS}

Forty patients were assessed during the study period. Of these, 33 patients were recruited and randomly allocated into the WBT $(n=17)$ and PBT $(n=16)$ groups. Reasons for exclusions and drop-outs are shown in the study profile (Fig. 1). Fifteen patients in the PBT group and fifteen patients in the WBT group completed the 4-week treatment program and the follow-up assessment at 8 weeks. Before treatment, there were no significant differences between the WBT and PBT groups with respect to demographic characteristics, mental state, and level of depression. However, disease severity measured by the Modified Rankin Scale was found to be higher in the PBT group (Table 1).

The functional balance performance scores of the patients in the WBT group were higher for the BBS and TUG tests performed before treatment (week 0). The results of the four different functional balance tests (BBS, TUG, DGI, and FRT) showed that both groups improved significantly after treatment (week 4). However, there was no significant difference between the groups after treatment (week 4). The patients in the PBT group showed a significantly lower results of the BBS and TUG tests in their follow-up measurements (week 8) (Table 2).

Both groups showed significant improvement in terms of the balance confidence (ABC) scale from baseline to after the treatment period (week 4). No significant difference was recorded between the two groups after treatment (weeks 4 and 8) (Table 2).
Table 1. Demographical and physical characteristics of patients

\begin{tabular}{|c|c|c|}
\hline & $\begin{array}{c}\text { WBT } \\
(n=15) \\
(X \pm S D)\end{array}$ & $\begin{array}{c}\text { PBT } \\
(\mathrm{n}=15) \\
(\mathrm{X} \pm \mathrm{SD})\end{array}$ \\
\hline \multicolumn{3}{|l|}{ Gender } \\
\hline Male & 6 & 7 \\
\hline Female & 9 & 8 \\
\hline \multicolumn{3}{|c|}{ Affected side } \\
\hline Right & 8 & 7 \\
\hline Left & 7 & 8 \\
\hline \multicolumn{3}{|c|}{ Age (years) } \\
\hline Mean & 62.80 & 56.60 \\
\hline $\mathrm{SD}$ & 10.87 & 16.42 \\
\hline \multicolumn{3}{|c|}{ Body mass index $\left(\mathrm{kg} / \mathrm{m}^{2}\right)$} \\
\hline Mean & 29.14 & 28.30 \\
\hline SD & 4.52 & 4.56 \\
\hline \multicolumn{3}{|c|}{ Duration (years) } \\
\hline Mean & 3.70 & 4.23 \\
\hline $\mathrm{SD}$ & 4.42 & 4.86 \\
\hline \multicolumn{3}{|c|}{ Modified Rankin Scale (0-6) } \\
\hline Mean & 1.80 & 2.40 \\
\hline SD & 0.77 & 0.82 \\
\hline \multicolumn{3}{|c|}{ Mini Mental Test (0-30) } \\
\hline Mean & 22.86 & 22.26 \\
\hline $\mathrm{SD}$ & 2.38 & 2.05 \\
\hline \multicolumn{3}{|c|}{ Beck Depression Inventory $(0-63)$} \\
\hline Mean & 14.00 & 14.00 \\
\hline SD & 6.14 & 7.58 \\
\hline
\end{tabular}

The activities of daily living measured with the FAI were found to be increased in both groups after treatment (week 4). When comparing the groups, no significant differences were found between them after treatment (weeks 4 and 8). The results at follow-up showed that ADL continued to improve in the PBT group despite cessation of treatment (week 8) (Table 2).

\section{DISCUSSION}

The main objective of this study was to compare the effects of balance training with an increasingly popular virtual reality based game technology, Nintendo Wii Fit (WBT), and progressive balance training (PBT) on balance functions, activity specific balance confidence, and activities of daily living in patients with chronic stroke. Although the two approaches tend to be more effective on different parameters of functional balance measures, there were no remarkable superiorities of either treatment approach over the other.

On the basis of the idea that visual feedback, which was used more intensely in the Wii Fit group, would have additional effects on symmetrical weight bearing on the paretic and nonparetic extremities ${ }^{36}$, the effects of the two treatment approaches on symmetrical weight distribution were 
1148 J. Phys. Ther. Sci. Vol. 27, No. 4, 2015

Table 2. Within-and between-group comparisons of all outcome measures

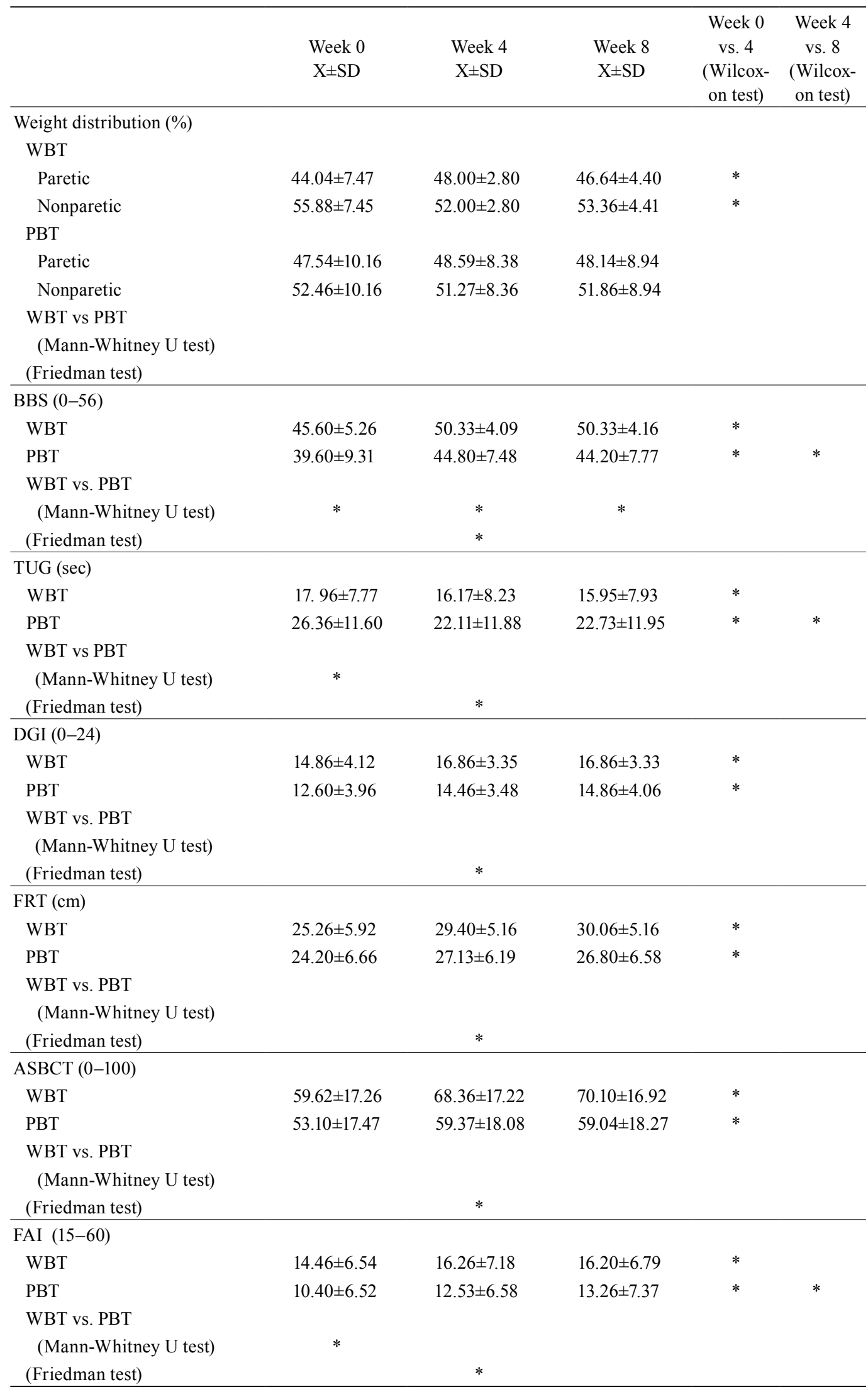

*Statistically significant values $(\mathrm{p} \leq 0.05)$ are indicated with an asterisk.

BBS: Berg Balance Scale; TUG: Timed Up and Go Test; DGI: Dynamic Gait Index; FRT: Functional Reach Test; ASBCT: Activity Specific Balance Confidence Test; FAI: Frenchay Activity Index 
compared in our study. Although the weight bearing on the paretic extremity was found to be improved and was more symmetrical in the WBT group, no significant superiority of either treatment method over the other was observed for the weight distribution of the patients. We speculate that the results might be due to the baseline weight distribution of the patients in our study. The average weight distribution of the patients on the nonparetic extremity at the beginning of this study was relatively symmetrical (52-55\%) compared with the values specified for stroke patients in the literature $(61-80 \%)^{11)}$. Moreover, the weight distribution was more symmetrical in the PBT group (52\%) than in the WBT group $(55 \%)$; thus the effects of the treatment methods might not have emerged exactly.

The balance exercises used in both treatment methods included weight shifting activities closely related to static balance, i.e., the ability to maintain a chosen posture with minimal postural sway ${ }^{10)}$. These exercises aims to improve postural control by increasing anteroposterior and mediolateral weight transfer and reducing postural sway, but do not especially focus on improving dynamic balance. As postural control is a prerequisite for most functional activities, weight shifting exercises aimed at improving postural control, may have significant effects on balance during functional activities. All of the functional balance measurements (BBS, TUG, DGI, and FRT) applied to the patients for that purpose showed that functional performance was improved in both groups. We supposed that training approaches emphasizing weight shifting abilities, whether using visual feedback (WBT) or not (PBT), provides benefits to both static and dynamic aspects of balance.

The measurements after 8 weeks showed that there was a decline in the BBS and TUG test results in the PBT group. In a case-control report of Deutsch et al., two individuals in the chronic phase post stroke received balance training with either a Nintendo Wii and Wii Fit program or standard of care balance and mobility program for 12 training (60-minute) sessions, and it was found that the patient who received the standard therapy maintained his improvements after treatment. It was propounded that the activities used for the treatment (balance and coordination exercises and outdoor activities e.g. crossing the road, walking in the busy areas, and market shopping) were transferred to real life activities due to the similarity between them, and thus the patient had used these activities after treatment ${ }^{22}$. Considering the activities of the study mentioned above, we did not include outdoor activities in addition to the balance exercises in our study; this may constitute a reason why the improvements were not maintained after treatment in our study.

'Balance confidence', defined as the perceived ability or confidence to perform an activity or action without falling ${ }^{37)}$, was found in our study to be improved in both groups after treatment. Bandura's theory identifies four factors affecting self-efficacy, that is, one's belief in one's ability to succeed in specific situations: performance accomplishments (physical practice), vicarious experience (mental practice), verbal persuasion (encouragement), and emotional sources (motivation) $^{38)}$. Associating these factors with falls-related self-efficacy, it can be said that both the PBT and WBT approaches may involve adequate physical practice, mental practice, encouragement, and motivation, which lead to improved balance confidence in patients.

The results for activities of daily living results indicate that the patients in both groups improved after treatment. In addition to this result, improvements in the PBT group proceeded after the cessation of treatment (week 8). It is known that the Wii Fit balance training method includes task-specific activities, though Wii Fit exercises are not very similar to daily life activities in many ways. Patients may perceive the Wii Fit activities as 'games', therefore, even though there are improvements in functional balance, these activities do not contribute to the transfer of improvements to daily life activities. In a further aspect, progressive balance training is more similar to daily life activities, and patients may perceive PBT activities as 'training' rather than a 'games', therefore, PBT may result in more improvement in patients' daily lives.

The limitations of this study include the fact that, the feedback given with Wii Fit may not be sufficient for patients to use normal movement strategies; therefore, physiotherapists should prevent abnormal patterns during activities. In another way, during the Wii Fit training, the need for a physiotherapist to help with symmetrical weight shifting poses a problem with respect to use of this technology at home. The main aim of this study was to use Wii Fit technology in order to reduce the need for one-to-one interaction between physiotherapist and patients; however, if there is a necessity for physiotherapists to correct the abnormal patters used by patients, it should be questioned whether this technology can be used at home or not. This study found that physiotherapist-assisted Wii Fit balance training is an effective method, but there is a need to compare the effects of Wii Fit balance training with and without any help from physiotherapists in future studies. Another limitation of this study was the disease severity, which was found to be higher in the PBT group. This limitation was due to the randomization procedure; therefore it could not be eliminated.

Some studies have asserted that although there are beneficial effects of using Wii Fit in rehabilitation, this technology may have some safety problems. Like the other commercial game systems, the Wii Fit system is a 'black box'; thus various parameters of the system cannot be controlled. In this sense, not being a rehabilitation-specific tool, being difficult for people with physical problems, allowing the use of abnormal movement patterns, having an incomprehensible scoring system, giving feedback that is not rehabilitation specific, and making degrading comments sometimes are some problems preventing the Wii Fit system from becoming widely used in rehabilitation ${ }^{22,39)}$. There are also reports of injuries arising from the use of Nintendo Wii game systems (metacarpal and metatarsal fractures, wrist and ankle traumas, clavicular fracture, patellar dislocation, muscle and tendon injuries, C7 fracture, stroke, and hemothorax) in the literature $^{40-46)}$. In this sense, there were no negative effects and/or any injuries attributable to use of Wii Fit in our study.

To our knowledge, this is the first study comparing the effectiveness of Wii Fit balance training (WBT) and progressive balance training (PBT) in addition to neurodevelopmental treatment approaches in patients with chronic stroke. The two treatment programs used in the current study were both 
found to be effective on balance functions, activity-specific balance confidence, and activities of daily living. When comparing the two treatment approaches, they seem to be effective on different parameters of balance performance, with no superiorities of either treatment approach over the other. Wii Fit balance treatment can be used as an effective method for patients with difficulty accessing treatment or for physiotherapists who require alternative methods of treatment.

\section{REFERENCES}

1) Feigin VL, Lawes CM, Bennett DA, et al.: Worldwide stroke incidence and early case fatality reported in 56 population-based studies: a systematic review. Lancet Neurol, 2009, 8: 355-369. [Medline] [CrossRef]

2) Adamson J, Beswick A, Ebrahim S: Is stroke the most common cause of disability? J Stroke Cerebrovasc Dis, 2004, 13: 171-177. [Medline] [CrossRef]

3) The Internet Stroke Center: Stroke Statistics http://www.strokecenter.org/ patients/about-stroke/stroke-statistics (Accessed Aug. 7, 2014)

4) Asplund K, Stegmayr B, Peltonen M: From the twentieth to the twenty-first century: a public health perspective on stroke. In: Ginsberg MD and Bogousslavsky J (eds) Cerebrovascular Disease Pathophysiology, Diagnosis, and Management. Oxford: Blackwell Science, 1998, pp 901-918.

5) Jackson D, Thornton H, Turner-Stokes L: Can young severely disabled stroke patients regain the ability to walk independently more than three months post stroke? Clin Rehabil, 2000, 14: 538-547. [Medline] [CrossRef]

6) Jørgensen HS, Nakayama H, Raaschou HO, et al.: Stroke. Neurologic and functional recovery the Copenhagen Stroke Study. Phys Med Rehabil Clin N Am, 1999, 10: 887-906. [Medline]

7) Jørgensen L, Engstad T, Jacobsen BK: Higher incidence of falls in longterm stroke survivors than in population controls: depressive symptoms predict falls after stroke. Stroke, 2002, 33: 542-547. [Medline] [CrossRef]

8) Hyndman D, Ashburn A, Stack E: Fall events among people with stroke living in the community: circumstances of falls and characteristics of fallers. Arch Phys Med Rehabil, 2002, 83: 165-170. [Medline] [CrossRef]

9) Weerdesteyn V, de Niet M, van Duijnhoven HJ, et al.: Falls in individuals with stroke. J Rehabil Res Dev, 2008, 45: 1195-1213. [Medline] [CrossRef]

10) Nichols DS: Balance retraining after stroke using force platform biofeedback. Phys Ther, 1997, 77: 553-558. [Medline]

11) Sackley CM, Bagulry BI: Visual feedback after stroke with the balance1performance monitor: two single-case studies. Clin Rehabil, 1993, 7 189-195. [CrossRef]

12) Belgen B, Beninato M, Sullivan PE, et al.: The association of balance capacity and falls self-efficacy with history of falling in communitydwelling people with chronic stroke. Arch Phys Med Rehabil, 2006, 87: 554-561. [Medline] [CrossRef]

13) Schmidt A, Wrisberg CA: Motor learning and performance. Illinois: Human Kinetics, 2000.

14) Diringer MN, Edwards DF, Mattson DT, et al.: Predictors of acute hospital costs for treatment of ischemic stroke in an academic center. Stroke, 1999 30: 724-728. [Medline] [CrossRef]

15) Kwakkel G: Impact of intensity of practice after stroke: issues for consideration. Disabil Rehabil, 2006, 28: 823-830. [Medline] [CrossRef]

16) Jack D, Boian R, Merians AS, et al.: Virtual reality-enhanced stroke rehabilitation. IEEE Trans Neural Syst Rehabil Eng, 2001, 9: 308-318. [Medline] [CrossRef]

17) Laver $K$, George $S$, Thomas $S$, et al.: Cochrane review: virtual reality for stroke rehabilitation. Eur J Phys Rehabil Med, 2012, 48: 523-530. [Medline]

18) Saposnik G, Teasell R, Mamdani M, et al. Stroke Outcome Research Canada (SORCan) Working Group: Effectiveness of virtual reality using Wii gaming technology in stroke rehabilitation: a pilot randomized clinica trial and proof of principle. Stroke, 2010, 41: 1477-1484. [Medline] [CrossRef]

19) Deutsch JE, Borbely M, Filler J, et al.: Use of a low-cost, commercially available gaming console (Wii) for rehabilitation of an adolescent with cerebral palsy. Phys Ther, 2008, 88: 1196-1207. [Medline] [CrossRef]

20) Butler DP, Willett K: Wii-habilitation: is there a role in trauma? Injury,
2010, 41: 883-885. [Medline] [CrossRef]

21) Sugarman H, Weisel-Eichler A: Use of the Wii Fit system for the treatmen of balance problems in the elderly: a feasibility study. Virtual Rehabilitation International Conference, 2009, 111-116.

22) Deutsch JE, Morrison RJ, Bowlby PG: Wii-based compared to standard of care balance and mobility rehabilitation for two individuals post-stroke. Virtual Rehabilitation International Conference, 2009, 117-120.

23) Cho KH, Lee KJ, Song CH: Virtual-reality balance training with a videogame system improves dynamic balance in chronic stroke patients. Tohoku J Exp Med, 2012, 228: 69-74. [Medline] [CrossRef]

24) Raine S, Meadows L, Lynch-Ellerington M: Bobath Concept: Theory and clinical practice in neurological rehabilitation. West Sussex: Wiley- Blackwell, 2009

25) Clark RA, Bryant AL, Pua Y, et al.: Validity and reliability of the Nintendo Wii Balance Board for assessment of standing balance. Gait Posture, 2010, 31: 307-310. [Medline] [CrossRef]

26) Langley FA, Mackintosh SF: Functional balance assessment of older community dwelling adults: a systematic review of the literature. Internet $J$ Allied Health Sci Pract, 2007, 5: 1-11

27) Blum L, Korner-Bitensky N: Usefulness of the Berg Balance Scale in stroke rehabilitation: a systematic review. Phys Ther, 2008, 88: 559-566. [Medline] [CrossRef]

28) Berg K, Wood-Dauphinee S, Williams JI, et al.: Measuring balance in the elderly: preliminary development of an instrument. Physiother Can, 1989, 41: 304-311. [CrossRef]

29) Podsiadlo D, Richardson S: The timed "Up \& Go": a test of basic functional mobility for frail elderly persons. J Am Geriatr Soc, 1991, 39: 142-148. [Medline]

30) Shumway-Cook A, Brauer S, Woollacott M: Predicting the probability for falls in community-dwelling older adults using the Timed Up \& Go Test Phys Ther, 2000, 80: 896-903. [Medline]

31) Shumway-Cook A, Woollacott M: Motor Control Theory and Applications. Baltimore: Williams and Wilkins, 1995.

32) O'Sullivan S, Schmitz T: Physical Rehabilitation. Philadelphia: F.A. Davis, 2007.

33) Duncan PW, Weiner DK, Chandler J, et al.: Functional reach: a new clinical measure of balance. J Gerontol, 1990, 45: M192-M197. [Medline] [CrossRef]

34) Powell LE, Myers AM: The Activities-specific Balance Confidence (ABC) Scale. J Gerontol A Biol Sci Med Sci, 1995, 50A: M28-M34. [Medline] [CrossRef]

35) Schuling J, de Haan R, Limburg M, et al.: The Frenchay Activities Index. Assessment of functional status in stroke patients. Stroke, 1993, 24: 1173-1177. [Medline] [CrossRef]

36) Van Peppen RP, Kortsmit M, Lindeman E, et al.: Effects of visual feedback therapy on postural control in bilateral standing after stroke: a systematic review. J Rehabil Med, 2006, 38: 3-9. [Medline] [CrossRef]

37) Tinetti ME, Richman D, Powell L: Falls efficacy as a measure of fear of falling. J Gerontol, 1990, 45: 239-243. [Medline] [CrossRef]

38) Bandura A: Self-efficacy: toward a unifying theory of behavioral change. Psychol Rev, 1977, 84: 191-215. [Medline] [CrossRef]

39) Anderson F, Annett M, Bischof WF: Lean on Wii: physical rehabilitation with virtual reality Wii peripherals. Stud Health Technol Inform, 2010, 154: 229-234. [Medline]

40) Sparks D, Chase D, Coughlin L: Wii have a problem: a review of self-reported Wii related injuries. Inform Prim Care, 2009, 17: 55-57. [Medline]

41) Cowley AD, Minnaar G: New generation computer games: watch out for Wii shoulder. BMJ, 2008, 336: 110. [Medline] [CrossRef]

42) Jones C, Hammig B: Case report: injuries associated with interactive game consoles: preliminary data. Phys Sportsmed, 2009, 37: 138-140. [Medline] [CrossRef]

43) Robinson RJ, Barron DA, Grainger AJ, et al.: Wii knee. Emerg Radiol, 2008, 15: 255-257. [Medline] [CrossRef]

44) Faivre A, Chapon F, Combaz X, et al.: Internal carotid artery dissection occurring during intensive practice with Wii video sports games. Neurology, 2009, 73: 1242-1243. [Medline] [CrossRef]

45) Brown CN, McKenna P: A Wii-related clay-shoveler's fracture. ScientificWorldJournal, 2009, 9: 1190-1191. [Medline] [CrossRef]

46) Peek AC, Ibrahim $T$, Abunasra $H$, et al.: White-out from a Wii: traumatic haemothorax sustained playing Nintendo Wii. Ann R Coll Surg Engl, 2008, 90: W9-10. [Medline] [CrossRef] 


\section{Appendix 1.}

The neurodevelopmental treatment approaches applied to both the WBT and PBT groups included mat activities and activities in sitting and standing positions.

- Activities intended for the upper extremity included shoulder mobilization, stretching, and goal-directed movements (e.g., crossing the midline to touch the opposite ear in a lying position and grasping a glass and moving it to the mouth in a sitting position)

- Activities intended for the trunk included strengthening trunk muscles, reaching activities, rotational trunk movements, and bridging activities (e.g., both legs on a mat, one leg on a mat and both legs on a balance ball)

- Activities intended for the lower extremity included ankle mobilization, stretching, and goal-directed movements (e.g., putting one leg to on the other to put on socks in a sitting position)

\section{Appendix 2.}

After the neurodevelopmental treatment approaches, Wii Fit balance exercises were performed in the WBT group. A Nintendo Wii game console, Wii Balance Board and a laptop connected to these devices were used. The balance exercises (Soccer Heading pictures 1.1. and 1.2.; Ski Slalom pictures 2.1. and 2.2.; and Balance Bubble pictures 3.1. and 3.2.) were selected from the Wii Fit Plus program. A user profile including the age, gender, and height was created for each subject, and a Mii character was selected for each of them. The subjects played each game 3 times and had a 5-minute break in between games. The exercises were as follows:

- Soccer Heading: Players try to head soccer balls but avoid cleats and panda heads as they get kicked at them by tilting their bodies left and right. The aim of the game is to 'tilt your body left and right to the soccer balls flying at you but dodge other flying objects'. Players have 80 seconds to complete the game. This game focuses on weight shifting in mediolateral directions, quick motor response ability, and improvement of attention and coordination by visual-auditory feedback.

- Ski Slalom: Players ski down a slalom course and try to navigate through flags by leaning left and right. The aim of the game is to 'lean left and right to go through the gates'. This game focuses on weight shifting in anteroposterior and mediolateral directions, changing and maintaining the position of the center of gravity, and improvement of attention and coordination by visual-auditory feedback.

- Balance Bubble: Players try to guide their Miis safely down to a river and through many obstacles like walls, rocks, and bees by leaning to the left, right, front, and back. The aim of the game is to 'shift your weight forward to move. You can also shift left and right'. Players have 90 seconds to complete the game. This game focus-

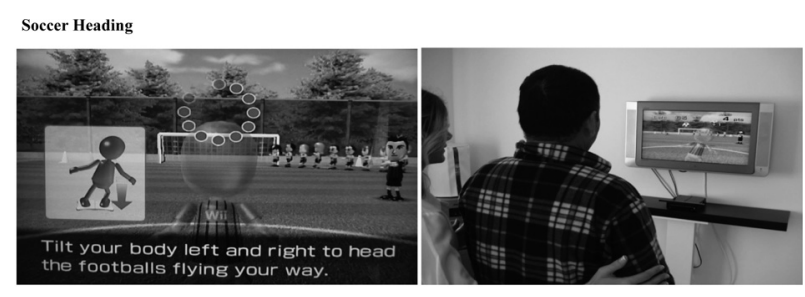

Picture 1.1.

Picture 1.2.
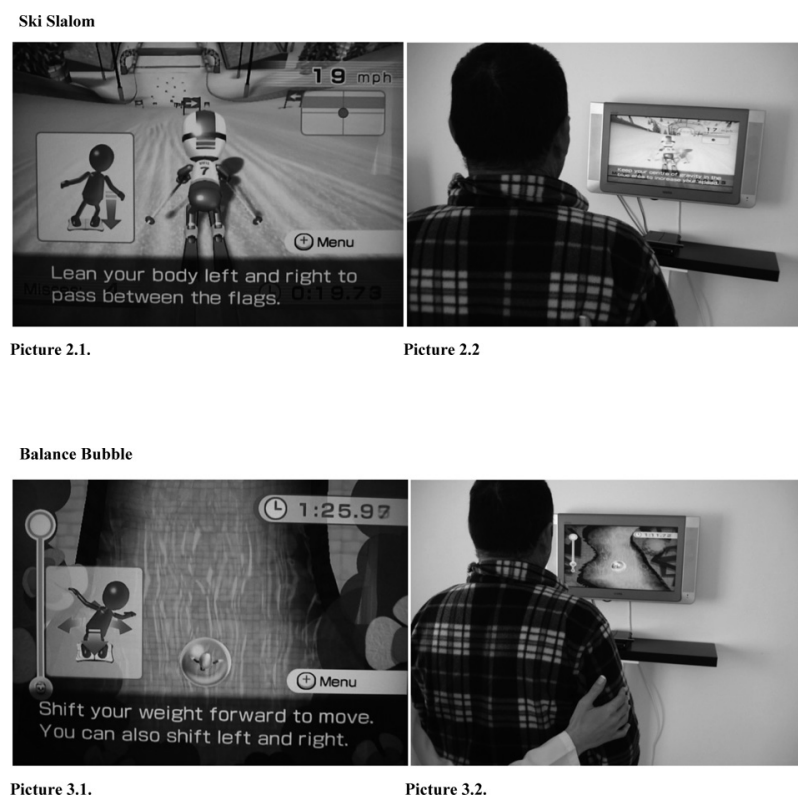

es on weight shifting in anteroposterior and mediolateral directions and improvement of attention, coordination, and postural control by visual-auditory feedback.

\section{Appendix 3.}

After the neurodevelopmental treatment approaches, progressive balance exercises were performed in the PBT group. All of the exercises were performed in a standing position. The movements were modified and applied according to the functional level of the patients. The speed and frequency of movement, foot positions, and ground features were modified to maximize the skills. These exercises were as follows;

- Head rotation and flexion (e.g., looking up at the ceiling)

- Trunk rotation (e.g., playing ball)

- Reaching actions (e.g., reaching forwards, backwards, or sideways to take an object)

- Weight shifting (e.g., shifting the body mass from one leg to the other)

- Stepping (e.g., stepping forwards or backwards)

- Single leg support (e.g., standing with either foot on the step)

- Standing on one leg (e.g., lifting one leg off the floor) 